\title{
Geçiş Kuramı Üzerine Anneliğe Geçişte İzlemsel Bir Olgu Çalışması
}

\author{
Figen TÜRK DÜDÜKCÜ ${ }^{1}$ (i) Fatma TAŞ ARSLAN² ${ }^{2}$ \\ ${ }^{1}$ KTO Karatay Üniversitesi, Sağlık Bilimleri Yüksekokulu, Hemşirelik Bölümü, Konya, Türkiye, \\ figen.turkdudukcu@karatay.edu.tr (Sorumlu Yazar/Corresponding Author) \\ ${ }^{2}$ Selçuk Üniversitesi, Hemşirelik Fakültesi, Hemşirelik Bölümü, Konya, Türkiye, fatmatas61@ @otmail.com
}

\begin{tabular}{|c|c|}
\hline Makale Bilgileri & ÖZ \\
\hline $\begin{array}{l}\text { Makale Geçmişi } \\
\text { Geliş: } 27.05 .2020 \\
\text { Kabul: } 26.10 .2020 \\
\text { Yayın: } 25.12 .2020 \\
\\
\text { Anahtar Kelimeler: } \\
\text { Geçiş kuramı, } \\
\text { Hemşire, } \\
\text { Ebeveynlik, } \\
\text { Bebek gelişimi. }\end{array}$ & $\begin{array}{l}\text { Geçiş, bilinen durumlardan, bilinmeyen yeni durumlara rol değişimini ifade eder. Teorik } \\
\text { açıdan bakıldığında; ebeveynliğe geçiş, belirli aşamaları ve kalıpları içeren gelişimsel bir } \\
\text { geçiştir. Bireyin kendinin ya da aile bireylerinin bir hastalık tanısı alması sağlık hastalık geçişi, } \\
\text { aile içinde yaşanan kayıplar ise durumsal geçişlerdir. Bu her bir geçiş zordur aynı zamanda } \\
\text { geçişi engelleyici birçok faktörü içinde barındırır. Bu çalışmada yaşındaki çoklu, ardışı ve eş } \\
\text { zamanlı gelişimsel, sağlık-hastalı ve durumsal geçişler yaşayan bayan SK Geçiş Kuramı'na } \\
\text { göre ele alınmış ve hemşirelik bakımı uygulanmıştır. Uygulanan hemşirelik bakımına gebelik } \\
\text { döneminde başlanmış ve doğum sonu dönemde de devam edilmiştir. Çalışma için Bayan } \\
\text { SK'dan yazılı ve sözel izin alınmıştır. Uygulanan hemşirelik bakımının sonuçları } \\
\text { doğrultusunda söylenebilir ki; Geçiş Kuramı hemşirelerin, geçişleri anlamalarını sağlamak için } \\
\text { uygun bir araç gibi görünmektedir. Özellikle ebeveynlere yeterli yardım ve destek sağlamak } \\
\text { için profesyonellerin uygun strateji ve uygulamaları belirlemelerine yardıme olma } \\
\text { potansiyeline sahiptir. Bu önemlidir, çünkü Meleis'in de belirttiği gibi hemşireliğin önemli bir } \\
\text { işlevi, insanlara yaşam geçişlerini yönetmelerinde yardımcı olmaktır. }\end{array}$ \\
\hline
\end{tabular}

\section{A Case Study on TransitionTheory in Transition to Motherhood}

\begin{tabular}{ll}
\hline ArticleInfo & ABSTRACT \\
\hline $\begin{array}{l}\text { Article History } \\
\text { Received: } 27.05 .2020 \\
\text { Accepted: } 26.10 .2020 \\
\text { Published: } 25.12 .2020\end{array}$ & $\begin{array}{l}\text { Transition refers to the change of role from known situations to new unknown situations. From a } \\
\text { theoretical point of view; The transition to parenthood is a developmental transition that involves } \\
\text { certain stages and patterns. The individual's or family members' diagnosis of a disease is the } \\
\text { transition from a health disease, and the losses in the family are situational transitions. Each } \\
\text { transition is difficult, and it includes many factors that inhibit transition. In this study, the woman } \\
\text { Keywords: }\end{array}$ \\
$\begin{array}{l}\text { who had multiple, consecutive and simultaneous developmental, health-disease and situational } \\
\text { transitions was handled according to SK Transition Theory and nursing care was applied. }\end{array}$ \\
$\begin{array}{l}\text { Nurse, } \\
\text { Parenting, }\end{array}$ \\
$\begin{array}{l}\text { Infant development. } \\
\text { verbal permission was obtained from Ms. SK for the study. In line with the results of the nursing } \\
\text { care applied, it can be said that; Transition Theory seems to be an appropriate tool to enable } \\
\text { nurses to understand transitions. It has the potential to help professionals identify appropriate } \\
\text { strategies and practices, especially to provide adequate assistance and support to parents. This is } \\
\text { important because, as Meleis points out, an important function of nursing is to help people } \\
\text { manage their life transitions. }\end{array}$
\end{tabular}

Atıf/Citation: Türk Düdükcü, F. \&Taş Arslan, F. (2020). Geçiş kuramı üzerine anneliğe geçişte izlemsel bir olgu çalışması, Genel Sağlık Bilimleri Dergisi, 2(3), 208-217. 


\section{MELEİS'IN GEÇIŞ KURAMI}

Geçiş, bilinen bir durumdan, bilinmeyen yeni başka bir duruma rol geçişini ifade etmektedir. Meleis ilk olarak 1960'ların ortalarında destekleyici gruplar yoluyla geçişlerle ilgilenmeye başlamıştır. O dönemde, gelişimsel veya sağlıkla ilgili sorunlarla başa çıkma konusunda eğitim ve destekleme yoluyla bireylere yardım etmeyi amaçlayan gruplar oluşmuştur. Hemşireler veya birtakım topluluk üyeleri tarafından yürütülen bu gruplar; bireylere yenidoğan bebek bakımında yardım, aile üyelerinden birinin kaybı, yıkıcı bir tıbbi tanı alma, mastektomi ya da kolostomi açılması gibi cerrahi işlemler ve bireylerin hayatında rutinin dışında gelişebilecek diğer sağlık deneyimlerinde birey ve ailelere destek verilmesi hizmetlerini vermektedirler. Meleis çalışma arkadaşlarıyla birlikte, destekleyici gruplarda hemşireler tarafından kullanılan yaygın- yaygın olmayan temalar, deneyimler, cevaplar ve stratejileri incelemiş ve bu destekleyici grupları oluşturma ve yürütmede evrensel özellikleri oluşturmaya ihtiyaç olduğunu saptamışlardır (Meleis, 2010). Meleis, Geçiş Kuramı'nda geçişin niteliği, geçiş durumları (engelleyici ve kolaylaştırıcı faktörler), yanıt biçimleri ve hemşirelik bakımının ana kavramları olduğunu belirtmiştir. Geçişin doğası; geçiş türünü, örüntülerini ve özelliklerini yansıtmaktadır. Geçişlerin; gelişimsel geçiş, sağlık-hastalık geçişi, durumsal geçiş ve kurumsal geçiş olarak 4 farklı türü vardır. Geçişler eş zamanlı, ardışı; ilişkili, ilişkisiz; tekli, çoklu örüntüler gösterebilir. Geçiş deneyiminin özellikleri farkındalık, katılım, değişim, zamanın akışı, önemli dönüm noktaları ve olaylardır. Tüm özellikler birbiriyle ilişkilidir. Farkındalık geçiş için önemli bir özelliktir fakat kişideki farkındalık geçişe engel değildir. Farkındalık olması ise sorumluluk almayı sağlayabilir. Sorumluluk alma ise geçişi kolaylaştırır. Değişim geçişin bir diğer temel özelliğidir. Tüm geçişler değişim sağlar ama tüm değişimler her zaman geçişin sonucu olmayabilir. Geçişler zaman içinde akarak devem eder. Bireylerin hayatındaki dönüm noktaları ve olaylar geçişe bakış açılarını belirler. Kişisel, topluluksal ve toplumsal şartlar geçişi kolaylaştırabilir ya da zorlaştırabilir ve böylece geçişin sonuçlarını etkiler. Gelişim göstergeleri ve sonuç göstergeleri geçiş deneyiminin yanıt biçimleridir. Etkileşim, bağlanma, özgüven, baş etmenin gelişmesi gelişim göstergeleridir. Yeni becerilerde yeterlilik ve esnek kimlik gelişiminin sağlanması sonuç göstergeleridir (Şekil 1).

Ebeveyn olmak; gelişimsel geçiştir, adölesan olmak; gelişimsel geçiştir, evlenmek; durumsal geçiştir, kronik hastalık tanısı konması; sağlık hastalık geçişidir. Tüm bu olaylar birbirinden farklı görünebilir, ama bir hemşirenin sorması gereken soru; "Bu olayların hepsinin ortak noktası ne olabilir?" olmalıdır. Bunlar geçiş sürecini başlatan değişikliklerdir. Geçiş yaşayan bireyler, aileler ve topluluklar farklı deneyimler, duygular yaşarlar ve geçiş deneyiminden sonra ne yaşayabilecekleri hakkında belirsizliklerle yüzleşirler. Beklentileri, konu hakkındaki bilgi düzeyleri, günlük rutinlerinde karşılaştıkları aksamalar sağlık ve iyilik hallerini etkiler (Meleis, 2019). Hemşirenin en önemli görevi, bireylere geçiş deneyimi sırasında yardım etmek ve sağlıklı geçişler yaşamalarını sağlamaktır. Geçiş deneyimi bireylerin yeni bilgi, beceri kazanmalarını, kendilerini yeniden tanımlamalarını ve yeni duruma adapte olmalarını gerektirir. Meleis hemşirelerin geçiş sonrası sağlkklı sonuçlar elde edebilmeleri için bu bireyler için yapabilecekleri üzerinde çalışmaları gerektiğini savunur.

Hemşireler, Geçiş Kuramını rehber alarak bireyin farkındalık düzeyini, alması gereken sorumlulukları, yaşanacak olan değişimi, geçişin başlangıç ve beklenen bitiş zamanını, kritik dönüm noktalarını değerlendirmeyi, değişimin günlük yaşam üzerindeki etkisini, bireyin geçirdiği aşamaları ve bu sürecin farklı aşamalarındaki tepkilerini anlarlar. Bu çalışmada çoklu ve zor bir geçiş yaşayan Bayan SK Geçiş Kuramı'na göre ele alınarak hemşirelik yaklaşımları belirtilmiştir.

\section{OLGU SUNUMU}

\section{Tanıtıcı Özellikler ve Öykü}

Bayan SK ile Temmuz 2018'de aile sağlığı merkezine rutin gebelik kontrolü için geldiğinde tanışıldı. Bayan SK 32 yaşında, ortaokul mezunu, 18 yaşında evlenmiş, 13 yaşında bir kızı ve 8 yaşında bir oğlu vardı. Üçüncü çocuğuna gebedir. Kızının 3 yıldır arteriovenözmalfarmosyon tanısı vardır. İlk iki gebeliği sorunsuz geçmiş ve başka çocuk istememektedir. Üçüncü kez gebe kaldığını öğrendiğinde gebeliğini sonlandırmak için birçok geleneksel yönteme başvurmuş, tıbbi müdahale istememiştir. Gebeliğinin üçüncü trimestrine kadar 
beslenme, egzersiz, vücut mekanikleri, gebelik izlemleri vb. konularında dikkat etmediğini belirtmiştir. Gebeliği ilerlediğinde plesantaprevia ve gestasyonel diyabet tanısı almıştır. Son bir yıl içinde babasını kaybetmiş ve eşiyle bazı sorunlar yaşamaya başladığını ifade etmiştir.

Bayan SK ile tanıştığımızda oldukça kaygılı olduğunu ve korktuğunu belirtti. "Sanırım kısa süre öncesine kadar bebeğimi istemediğim için tüm bunlar bir ceza olarak başıma geldi" diyerek içinde bulunduğu durumdan pişmanlığını belirtti. Gebeliğin kalan süresinde s1k s1k kontrollere gitti. Gebeliğin 35. haftasında kontraksiyonlarının başlaması ve bebekte stres belirtileri olması üzerine acil sezaryene alındı. Doğduğunda bebeğin apgar puanı 4 'tü. Arama, emme, yutma refleksleri yoktu ve moro refleksi ise zayıftı. Bebeğe intrauterin gelişim geriliği tanısı kondu. Bebek yaklaşık olarak iki ay bir üniversite hastanesinin yenidoğan yoğun bakım ünitesinde izlendi. Taburcu olduğunda bebek günün 23 saatten fazlasını uyuyarak geçiriyor ve nazogastrikkateterle besleniyordu. Bayan SK doğumdan sonraki iki ay boyunca sağarak nazogastrikkateterle bebeğinin anne sütü almasını sağladı. Bayan SK sürekli uyuyan bebeğini beslerken ve bakımıyla ilgilenirken oldukça fazla zorlandığını ifade etti. Kendini suçlu hissediyordu. Bundan dolayı kendi diyabetik diyetine, egzersizlerine ve takiplerine dikkat etmiyordu. Bayan SK postpartum beşinci ayda bir gece diyabetik ketoasidoz tanısı ile yoğun bakıma alındı. Glaskow koma skala puanı 7 idi. İki gün bilinci kapalı olarak izlendi, on gün kan glikoz seviyesi düzenlenemedi. İki hafta hastanede kaldıktan sonra taburcu edildi. Ve sonrasında sık sık kontrollerine gitmeye başladı.

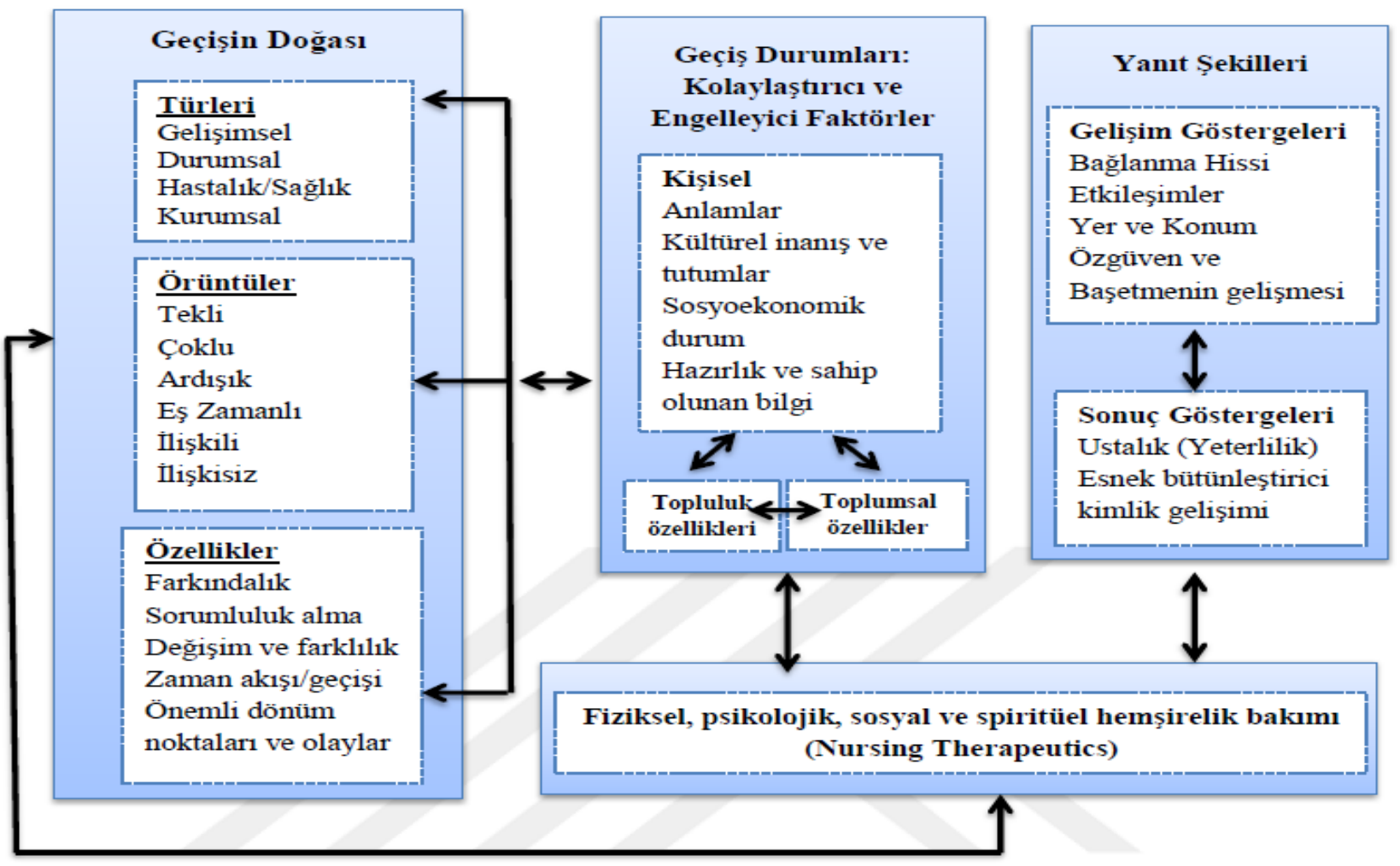

Şekil 1: Geçişler Kuramı: Hemşirelik Araştırmalarında Orta Düzey ve Duruma Özel Kuramlar ve Uygulamaları (Meleis 2010).

\section{GEÇIŞ KURAMI'NIN KAVRAMSAL ÇERÇEVESI VE OLGU}

\section{Geçişin Niteliği: Türleri ve Örüntüsü}

Geçiş Kuram1, gelişimsel bir geçiş türü olan ebeveynliğe geçişi (Barimani ve ark., 2017; Meleis, 2010), sağlık-hastalık ve durumsal geçişleri anlamaları için hemşirelere rehberlik eder (Meleis, 2010). Geçiş Kuramı'nın kavramsal çerçevesinde Bayan SK'nın yaşadığı geçiş incelendiğinde, son birkaç yıl içinde babasını kaybetmesi, durumsal geçiş; kızının aldığı arteriovenözmalfarmosyon tanısı, gestasyonel diyabet ve bebeğinde gelişim geriliği tanısı, sağlık-hastalık geçişi; yeniden anneliğe geçiş yani gelişimsel geçiş yaşadığı görülmektedir. Bayan SK'nın 
sağlık hastalık geçişleri ve anneliğe geçişi hala devam eden süreçlerdir. Geçiş kuramının niteliğine göre Bayan SK'nıngeçişleri ardışık, ilişskili ve çoklu geçişlerdir.

\section{Geçişin Niteliği: Geçişin özellikleri}

Farkındalık: Meleis geçiş deneyiminde farkındalığın zorunlu bir koşul olmadığını belirtmektedir. Farkındalık geçiş sonunda pozitif sonuçlar elde etmek için temel kavramlardan biridir (Meleis, 2010). Bayan SK yaşadı̆̆ geçişlerin farkındaydı ve bunlar yaşamak istemediği geçişlerdi. Bunları yaşamak zorunda kalmanın, değiştirememenin ve daha önemlisi her şeyin farkında olmanın çok zor olduğunu ifade etti. Sorumluluk Alma (Katılım): Alınan sorumluluğun düzeyi geçişin bir başka özelliğidir. Sorumluluk, kişinin geçişe katılımını gösteren derecedir (Meleis, 2010). Bayan SK bir kadın ve anne olarak alması gereken sorumlulukların farkındadır. Ancak gebeliğinin üçüncü trimestrine kadar beslenme, egzersiz, vücut mekanikleri, gebelik izlemleri vb. konularda sorumluluklarını yerine getirmemiştir. Bu geçiş döneminde eşinin alması gereken bazı sorumlulukları da almış durumdadır. Eşinden bu süreçte destek alamamış olduğu için hem üzgün hem de eşine karşı öfkelidir. Bir bebeğin sorumluluğunu almayı, bakımını yapmayı iki kez deneyimlemiş olmasına rağmen üçüncü bebeğinde aldığı sorumluluklar daha fazla ve daha zordur. Bebeğini emzirmek istiyor ancak bebeğin emme ve yutma refleksleri yoktur. Bebekte aspirasyon riski vardır ve bebeğin gelişimini desteklemeyi ve güvenliğini sağlamada nelere dikkat etmesi gerektiğini bilmemektedir. Yenidoğan bakım konusunda annelere verilen eğitimler anne ve bebek sağlığını geliştirmekte, yenidoğan bakımı konusunda anne bilgisini arttırmakta ve primipar annelerde anksiyeteyi azaltmaktadır (Shrestha, Adachi, Petrini, Shrestha, \& Khagi, 2016). Yapılan bir çalışmada ilk defa anne olan kadınların (yenidoğan banyosu, göbek kordonu bakımı, emzirme ve kolik gibi) birçok konuda bilgi ihtiyaçları olduğu belirlenmiştir (Silva \& Carneiro, 2018). Bayan SK üçüncü kez anne oldu. Ancak "daha önceki bebeklerim sağlıklı doğduğu için ilk çocuğumun bakımı bile bu kadar zor değildi" diyerek aldığı sorumluluğun zorluğunu ifade etti. Değişim ve Farklılık: Geçişin önemli özelliklerindendir. Birbirine yakın anlamlar gibi görünse de eş anlamlı değildirler. Bu özellikler birbirinin yerine kullanılmamalıdır. Tüm geçişlerde değişim vardır ancak tüm değişimler geçiş ile ilgili olamayabilir. Yeni rollere ve durumlara adaptasyon değişim gerektirir (Meleis, 2010). Hemşireler bu değişimlerin ve geçiş sürecinin merkezindedir. Değişime hazırlıklı ve karşı karşıya kalan bireyleri her zaman destekler. Değişim, bir insanın hayatını olumlu yönde değiştiren yolların değerlendirilmesine olanak tanır. Farklılık, çevreyi farklı şekilde görmeyi ya da farklı olma algısını ifade eder (Meleis, 2019). Bayan SK'nın yaşadığı geçişler hem kendi hem de ailesinin yaşamında büyük değişim ve farklılıklar ortaya çıkaracak geçişlerdir. Zaman Akışı: Geçişler kronolojik olarak hareket ve akış halindedir. Geçiş deneyiminin zaman içinde sınırları her zaman net olmayabilir. Her bireyin geçiş deneyimi kişiseldir, özeldir ve aynı zamanlarda sonlanmaz (Meleis, 2010). Bayan SK'nın yaşadığı geçişler uzun dönemli süreçlerdir ve geçiş deneyimlerini değerlendirirken devam eden süreçler olduğunu göz önünde bulundurulmalıdır. Önemli Dönüm Noktalart ve Olaylar: Uygun müdahalelerin belirlenebilmesi için kritik noktaların veya dönüm noktalarının belirlenmesi gerekir. Kritik noktalar, herkes için farklı olabilir, değişimin farklı doğasını ve özelliklerini yansıtabilir (Meleis, 2010, 2019). Bayan SK'dan yaşamındaki önemli dönüm noktalarını ve olayları algllama durumunu değerlendirmesi istendi. Gestasyonel diyabet ve plesantaprevia tanısl almadan önceki en önemli yaşam olayın babasını kaybetmesi olarak belirtti. Gestasyonel diyabet ve plesantaprevia tanısı konduktan sonra en önemli yaşam olayının bebeğinin sağlı̆̆ı olduğunu söyledi. Ancak yaşadı̆̆ diyabetik ketoasidoz koması deneyiminden sonra en önemli olayın kendi sağllğg olduğunu çünkü çocuklarının bakımı ve sağlı̆̆ının buna bă̆lı olduğunu fark ettiğini söyledi

\section{Geçiş durumları: Geçişi Kolaylaştıran ve Engelleyen Faktörler}

Kişisel, toplumsal ve topluluksal durumlar geçiş sürecini ve geçişin sonuçlarını kolaylaştırabilir ya da engelleyebilir (Meleis, 2010). Barimani ve arkadaşları (2017) ebeveynliğe geçişin aile yaşamı üzerine olumlu ya da olumsuz etkileri olabileceğini bu nedenle geçişi kolaylaştıran ya da engelleyen faktörlerin anlaşılmasının hemşirelere başarılı geçiş deneyimini desteklemede yardımcı olabileceğini belirtmiştir (Barimani ve ark., 2017). 


\section{Kişisel Özellikler}

Bireyin geçişe verdiği anlam önemlidir (Barimani ve ark., 2017; Meleis, 2010). Bayan SK'nın kısa bir zaman dilimi içinde istemediği birçok geçiş yaşadığ 1 ve hem kendi hem çocuklarının sağlık sorunlarından dolayı ilk görüşmelerimizde geçişlere olumsuz anlamlar yüklediği belirlendi. Bunlar geçişi engelleyen faktörlerdi. Bu doğrultuda bayan SK'nın öncelikli olarak kendi sağlık sorunlarını kabul ederek sağlı̆̆ını koruması ve geliştirmesi, bebeğinin gelişimini desteklemesi ve güvenliğini sağlaması için yapması gerekenleri öğrenmesi ve uygulaması böylece sağlıklı bir geçiş yaşaması planlandı. Ancak gerçekçi olmayan beklentiler oluşturmamak için çaba sarfedildi. Barimani ve arkadaşlarının (2017) çalışmasında ebeveynlik konusundaki yanlış/gerçekçi olmayan beklentiler, stres, emzirme ve uykusuzluk, tecrübesiz ve hazırlıksız olmak, gerçeklik hakkında bilgi sahibi olmamak gibi faktörlerin geçişi engelleyen özellikler olduğu bulunmuştur (Barimani ve ark., 2017). Bayan SK bebeğin gelişim geriliği tanısı almış olmasından dolayı kendini normalden daha güçsüz ve çaresiz hissettiğini belirtti. Eğitim içeriğimizde Bayan SK'nın diyetine uyum durumunu, diyabetik ilaçlarını ve insülin uygulamaları kontrol edildi. Bebeğin gelişimini destekleme (kaba motor, ince motor, dil ve kişisel-sosyal alan), uyku güvenliği, kaza ve yaralanmalardan, aspirasyon riskinden, enfeksiyonlardan koruma, beslenme, bağışıklama ve taramalar gibi konuları ele alarak anne hem hazırlandı hem de gerçekçi beklentiler oluşturması için rehberlik edildi. Anne olmak bir kadın için hem güçlü hem savunmasız bir durumdur (Davis-Floyd, 2004). Bayan SK'nın güçlü yönleri desteklendi, güçsüzlüğe yol açabilecek durumlara hazırlandı.

\section{Topluluk Özellikleri}

Yaşanılan çevredeki topluluk özellikleri geçişi kolaylaştıran ya da zorlaştıran etmenler olabilir. Topluluktaki rol modeller, güvenilir kişilerden alınan tavsiyeler, sağlık personeli ve elde edilen güvenilir bilgiler geçişi kolaylaştırabilir. Destek ve bilgi yetersizliği ise engelleyici faktörlerdendir (Barimani ve ark., 2017). Bayan SK en büyük destekçisinin babası olduğunu, babasını kaybettiğinde büyük bir yıkım ve güçsüzlük hissettiğini belirtti. Yaşadığı kayıp, bebeğinin gelişim geriliği ve kızının arteriovenözmalfarmosyon tanıları Bayan SK için engelleyici birer faktördü. Bunun yanında kızının varlığından güç aldığını, çocuklarının bakım ve eğitiminin kendisine bağl1 olduğunu belirtti. Bu durumlar da geçişi kolaylaştıran faktörlerdi.

\section{Toplumsal Özellikler}

Toplumsal koşullar geçiş için önemlidir. Her ne kadar toplumsal kurallar ve kültür, yeni anneden beklenenler hakkında birtakım bilgiler sağlasa da, annelikle ilgili kurallar ya da kılavuzlar yoktur (Mercer, 1981). Bu nedenle, birçok kadın deneme yanılma yoluyla doğru olana ulaşmaya çalışır (Beck, 1996). Bu durum geçiş deneyimi için engelleyici olabilir. Özellikle Bayan SK gibi çoklu ve zor geçişler yaşayan kadınlar toplumsal beklentileri karşılamakta zorlanabilirler.

\section{GEÇiŞ KURAMINA GÖRE FİİKSEL, PSIKOLOJIK, SOSYAL, SPİRITÜEL HEMŞİRELIK BAKIMI}

Bayan SK ile gebelik 28. ve 34. haftalarında, doğum sonu ikinci ayda, üçüncü ayda, altıncı ayda, sekiz ve on ikinci aylarda toplam yedi görüşme yapıldı ve hemşirelik bakımı uygulandı. Bayan SK'ya emzirme, anne sütünü sağma ve saklama, doğuma hazırlık, bebek gelişiminin desteklenmesi, yenidoğan taramaları, aşılama, bebek sağlı̆̆ının korunması, bebeklerde sık karşılaşılan sorunlar, bebek güvenliğinin sağlanması konularında eğitim verildi. Eğitimlerde powerpoint sunusu, meme maketi, bebek maketi ve gelişim destekleme materyalleri kullanıldı. Eğitim sonunda bebek sağlığının geliştirilmesine yönelik bir doktora tez programı kapsamında altı uzmanın görüşü alınarak geliştirilen eğitim kitapçığı verildi. Ebeveynlerin hemşirelere erişilebilirliği ve ebeveynlere bilgi amaçlı gönderilen kısa mesajlar pediatrik hasta grubunda bakımın devamlılığını sağlamakta ve bakımın kalitesini arttırmaktadır (Ladley ve ark., 2018). Bu nedenle ihtiyacı olması durumunda bize ulaşabileceği telefon numarası ve eğitim kitapçığı verildi. İlk tanışmada gestasyonel diyabet ve plesantaprevia hakkında eğitim verildi. Ve toplam 4 eğitim oturumu planlandı. İkinci kez 34. gebelik haftasında görüşüldü. Bayan SK'nın 35. gebelik haftasında 2800 gr bir erkek bebeği oldu. Yaşadığı sağlık sorunları ve bebeğinin aldığı gelişim geriliği tanısından sonra eğitim oturumların sıklığı artırıldı. Doğumdan sonraki ikinci ayın sonunda üçüncü kez yapılan 
görüşmeye eşiyle birlikte geldi. Değerlendirme ve eğitim yapıldı. Daha önce verilen eğitimin geri bildirimleri alındı. Oldukça yorgun görünüyordu. Bebeğini emziremediği, bebeği sürekli uyuduğu ve bebeğiyle iletişim kuramadığını düşündüğü için mutsuzdu. Bebek Denver II gelişim tarama testi ile değerlendirildiğinde; dört gelişim alanında da (kaba motor, ince motor, dil ve kişisel-sosyal alan), gerilik tespit edildi. Anne bebeğin gelişimini desteklemek için gereken uygulamaların birçoğunu yapamadığını ifade etti. Görüşmede bebeğinin bu desteğe sağlıklı bebeklerden daha fazla ihtiyacı olduğu belirtildi. Sonraki randevuya kadar yapması gereken uygulamalar (bebeğin beş duyu organını uygun biçimde uyarabilmesi için görsel, işitsel, dokunsal, koku ve emzirme eğitimleri) tekrar planlandı. Bunların yanında aspirasyon riskine karşı ilk yardım eğitimi verildi. Meleis'in belirttiği geçişi kolaylaştıracak olan sosyal destek sistemi olarak eşine de bebeğin beslenmesine ve banyosuna yardım etme, her gün kucağına alma, konuşma vb. bazı görevler verildi. Bayan SK her gün düzenli ve sürekli olarak bebeği ile konuştu, ninni ve şarkı söyledi, aile üyelerinin de konuşmasını sağladı (işitsel uyaran: dil gelişimi ve kişisel-sosyal gelişim için). Bebeğine her gün bir süre masaj yaptı: yanaklarına dokundu, başını okşadı, el ve ayak parmaklarını açıp kapadı (dokunsal uyaran: kaba ve ince motor gelişimi için). Bebeğini sık sık kucağına alarak anne kokusunu almasını sağladı. Parfüm, deodorant, kokulu deterjanlardan uzak durdu (koku uyaranı: kişisel-sosyal gelişim için). Nazogastrik ile beslemesine rağmen bebeğinin ağzına günde iki-üç defa formül mama damlattı, ağız bakımı verdi (tat uyaranı: kişisel-sosyal gelişim için).

Doğum sonu üçüncü ayda yapılan dördüncü görüşmede Bayan SK ve eşi bebeğin gelişimini destekleme, besleme, güvenliğini sağlama vb. konulardaverdiğimiz sorumlulukları yerine getirmişlerdi. Sağlıklı bir yenidoğan günün yaklaşık 8-10 saatini gece olmak üzere toplam 16 saatini uykuda geçirir, iki-üçüncü aylarda bu süre 10 saate kadar azalır (Paruthi ve ark., 2016). Bayan SK'nın bebeğinde belirgin bir değişim başlamıştı. Bebeğin uyanık kalma süresi artmıştı (günde iki saat kadar). Uyanık kaldığı süreler içinde annesi ile göz teması kurmaya başlamıştı. Bayan SK bebeğindeki değişimden dolayı hem mutlu hem de memnundu. Bebeğin gelişimini destekleme konusunda oldukça istekliydi. Emme refleksi hala yoktu ancak yutma refleksi gelişmeye başladı ve oral beslenmeye geçildi. Denver II gelişim tarama testi ile değerlendirmemizde; kişisel-sosyal (yüze bakma, karşılıklı gülme) ve dil (zile tepki, agulama), ince motor (orta hatta kadar izleme) gelişiminde ilerleme başlamıştı. Kaba motor gelişiminde (ekstremitelerde eşit hareketler) gerilik devam ediyordu. Gelişmeler konusunda Bayan SK ve eşine geri bildirim vererek sonraki görüşmeye kadar yapacakları uygulamalar planlandı. Bir önceki uygulamalara ek olarak bebeğe görsel uyaran (farklı, canlı ve zıt renklerdeki cisimleri gösterme, göz teması kurma, aynada kendini gösterme, renkli resimli kitapları göstererek okuma gibi) ve ekstremite gelişimi için egzersizler önerildi. Doğum sonu altıncı aya randevu verildi.

Doğum sonu altıncı ay beşinci değerlendirme yapıldı. Denver II gelişim tarama testi ile değerlendirmemizde; kişisel-sosyal alan değerlendirmesine yüze bakma, karşılıklı gülme ve ellere bakma vardı, erişemediği oyuncağa uzanmıyordu. Dil gelişimi değerlendirmesinde; zile tepki, agulama, tıkırtı sesine dönme, ismi fisıldanınca dönme vardı, tek hece söyleme, kendine özgü dil yoktu. İnce motor gelişimi değerlendirmesinde; 180 derece izleme, ellerini birleştirme vardı, çıngırağı kavrama, üzüme bakma yoktu. Kaba motor gelişimi değerlendirmesinde; başı 45 derece kaldırma, başı dik oturma, oturtulurken başını düşürmeme, başı doksan derece kaldırma vardı, kol desteği ile göğsü kaldırma, dönme yoktu. Gelişim geriliği azalmış ve bebeğin gelişiminde ilerleme başlamıştı. Bu ayda tamamlayıcı beslenme eğitimi de verildi.

Doğum sonu sekizinci ay altınc1 değerlendirme yapıldı. Denver II gelişim tarama testi ile değerlendirmemizde; bebeğin dört alanda gelişiminin yaşıtlarına yaklaşmaya başladığı tespit edildi. Bayan SK tüm uygulamalara devam etti. Bebeğindeki ilerlemeleri görmekten ve eşinden yardım alabilmesinden dolayı artık mutlu olduğunu ifade etti. Eşi de daha önce katıldığı eğitimden etkilendiğini ve farkındalık yaşadığını ifade etti. Bayan SK için engelleyici faktörler kontrol altına alınmıştı. İlk görüşmelerdeki eşi ve bebeği ile ilgili olan olumsuz, mutsuz ve memnuniyetsiz durumu değişmiş, etkileşim içindeydiler.

Doğum sonu on ikinci ayda yedinci değerlendirme yapıldı. Denver II gelişim tarama testi ile değerlendirmemizde; bebeğin dört alanda gelişiminin normal sınırlar içinde olduğu belirlendi. Tüm aile birlikte bebekteki değişimi adım adım izlemiş, değişime tanık olmuş ve bu durum aileyi birbirine yaklaştırmıştı. Aynı 
zamanda Bayan SK diyetine dikkat ediyor, ilaçlarını düzenli alıyor, egzersizlerini yapıyor ve kızının kontrollerini de düzenli takip ediyordu.

\section{Sağlıklı Bir Geçişin Süreç Göstergeleri}

Meleis'e göre gelişim göstergeleri geçişin nasıl ilerlediğini gösteren ölçülebilir göstergelerdir. Gelişim göstergeleri; etkileşim, bağlanma hissi, konumlandırma, özgüven ve baş etme geliştirmeyi kapsamaktadır (Meleis, 2010). Etkileşim; Bayan SK gebeliğin ilk iki trimestrinde bebeğini istememiş ve herhangi bir etkileşime girmeyi reddetmişti. Düşük yapmak için farklı yollar aramıştı. Ancak doğumdan sonra bebeği ile etkileşime girmek istedi, bebeği sürekli olarak uyuduğu için bunu sağlayamadı. Gelişimi destekleme uygulamaları ile birlikte bebeğindeki değişimleri görerek bebeği ile etkileşime girebilmeye başlamış ve bebeğinin sağllğı için daha fazla çaba sarf etmiştir. Bağlanma Hissi; Meleis bağlanma hissi kavramlarından biri sağlık çalışanlarına olan güvenden bahsetmiştir (Meleis, 2010). Bayan SK'nın ihtiyaç duyması halinde bize ulaştı, sorularına yanıt aldı. Sağlık personeline bağlanma olumlu geçişin bir göstergesidir. Bebeğinin bakımı ve gelişimi için öğrendiği uygulamaların olumlu sonuç vermesi sağlık çalışanlarına da bağlanma durumunu arttırdı. Ö̈gü̈ven ve Başetmenin Gelişmesi;Geçiş sürecinin doğasını olumlu yansıtan bir diğer boyut, bireyin sürece katılımıyla özgüven düzeyindeki artıştır (Meleis, 2010). Kendine güveni artan Bayan SK bebeğinin bakımı konusundaki zorluklarla baş edebildi. Aynı zamanda diyetine uyum sağlamak, insülinini düzenli uygulayarak kan glikoz düzeyini dengede tutmak gibi kendi sağlık uygulamalarını sürdürdü.

\section{Sağlıklı Bir Geçişin Gelişim (Sonuç) Göstergeleri}

Sağlıklı geçiş için gereken iki sonuç göstergesinden ilki yeni becerilerde ustalıktır, ikincisi ise esnek bütünleştirici kimlik geliştirilmesidir. Bu gelişim göstergeleri yaşam kalitesini yükseltir (Meleis, 2010). Bayan SK öncelikli olarak bebeğini kabullendi. Bebeğinin bakımını, güvenliğini, gelişimini nasıl sağlayabileceğini öğrendi ve uyguladı. Karşılaştığı sorunlarla baş etti, bebeğinin gelişimi için önerdiğimiz uygulamaları yerine getirdi, uyku güvenliğine dikkat etti, düşme ve kazaların önlenmesi için gerekli tedbirleri aldı. Bu durumlar ustalık göstergeleridir. Ancak Bayan SK'ın ikinci ayın sonunda sütü azalarak kesildi ve bebeğine daha uzun süre anne sütü veremedi. Çünkü bebeği emmediği için sütünün kesileceğine inandı. Esnek Kimlik Gelişimi;Hemşire bireyin sağlı̆̆ını kapsamlı bir şekilde değerlendirmeli ve girişimlere yönelik doğru karar vermelidir. Kadınlar çoklu rollerini sosyal, kültürel, politik, ekonomik baskı ve kısıtlamalara rağmen nasıl entegre ettiklerini iyi anlamalıdırlar (Meleis, 2010). Bayan SK'ya verdiğimiz bebek gelişimini destekleme ve güvenliğini sağlama eğitimi ebeveynliğe geçişi kolaylaştırdı.

Sonuç olarak; Geçiş Kuramı hemşirelerin farklı geçiş deneyimlerini anlamalarını sağlamak için uygun bir araç gibi görünmektedir. Ayrıca, ebeveynlere yeterli yardım ve destek sağlamak için hemşirelerin uygun strateji ve uygulamaları belirlemelerine yardımcı olma potansiyeline sahiptir. Bu önemlidir, çünkü Meleis'in de belirttiği gibi hemşireliğin önemli bir işlevi, insanlara yaşam geçişlerini yönetmelerinde yardımcı olmaktır. Gelecek çalışmalarda geçiş deneyimlerini tam olarak anlamak için boylamsal/uzunlamasına daha fazla çalışma yapılmasını önermekteyiz.

\section{Finansal Destek}

Çalışmada herhangi bir finansal destek alınmamıştır.

\section{Çıkar çatışması}

Yazarlar arasında herhangi bir çıkar çatışması yoktur.

\section{Yazarlık Katkıları:}

Tasarım/Design: F.T.D.; Veri toplama veya Veri Girişi Yapma/Data Collection or Processing: F.T.D.;

Analiz ve Yorum/ Analysis and Interpretation: F.T.D., F.T.A.; Literatür Tarama/Literature Search: F.T.D.; Yazma/Writing: F.T.D., F.T.A. 


\section{KAYNAKÇA}

Barimani, M., Vikstrom, A., Rosander, M., Forslund Frykedal, K., \& Berlin, A. (2017). Facilitating and inhibiting factors in transition to parenthood - ways in which health professionals can support parents. Scand J Caring Sci, 31(3), 537-546. doi:10.1111/scs.12367

Beck, C. T. (1996). A meta-analysis of predictors of postpartum depression. Nursing Research, 45(5), 297-303.

Davis-Floyd, R. E. (2004). Birth as an American rite of Passage: With a new preface: Univ of California Press.

Meleis, A. I. (2010). Transitions theory: Middle Range and Situation Specific Theories in Nursing Research and Practice: Springer publishing company.

Meleis, A. I. (2019). Facilitating and Managing Transitions: An Imperative for Quality Care. Investigación en Enfermería: Imagen y Desarrollo, 21(1).

Mercer, R. T. (1981). A theoretical framework for studying factors that impact on the maternal role. Nursing Research, 30(2), 73-77.

Paruthi, S., Brooks, L. J., D'Ambrosio, C., Hall, W. A., Kotagal, S., Lloyd, R. M., . . Quan, S. F. (2016). Recommended amount of sleep for pediatric populations: a consensus statement of the American Academy of Sleep Medicine. Journal of Clinical Sleep Medicine, 12(6), 785-786.

Shrestha, S., Adachi, K., Petrini, M. A., Shrestha, S., \& Khagi, B. R. (2016). Development and evaluation of a newborn care education programme in primiparous mothers in Nepal. Midwifery, 42, 21-28.

Silva, C. D. S. E., \& Carneiro, M. D. N. F. (2018). Pais pela primeira vez: aquisição de competências parentais. Acta Paulista de Enfermagem, 31(4), 366-373. doi:10.1590/1982-0194201800052. 


\section{EXTENDED ABSTRACT}

Ms. SK married at the age of 32, secondary school graduate, 18 years old. There are 2 children, one girl and the other boy. Her 13-year-old daughter has been diagnosed with arteriovenous malpromotion for 3 years. When her pregnancy progressed, she was diagnosed with plesanta previa and gestational diabetes. It is experiencing a difficult transition period. After birth, her baby did not have long search, sucking, swallowing reflexes and the moro reflex was weak. The baby was monitored in the neonatal intensive care unit of a university hospital for about two months. The baby was diagnosed with abnormal development. Ms. SK felt guilty. Transition Theory guides nurses to understand transitions.

When the transition experienced by Mrs. SK in the conceptual framework of the Transition Theory, it is seen that there is a situational transition, a health-disease transition and a developmental transition. Mrs. SK's transition to health disease and transition to motherhood are still ongoing processes. According to the nature of the transition theory, the transitions of Mrs. SK are consecutive, related and multiple transitions.

\section{Case Report}

\section{Introductory Features And Story}

Ms. She is pregnant with her third child. The first two pregnancies were uneventful and she does not want another child. When she learned that she was pregnant for the third time, she applied many traditional methods to terminate her pregnancy and did not seek medical intervention. Until the third trimester of pregnancy, nutrition, exercise, body mechanics, pregnancy monitoring, etc.

\section{The Conceptual Framework And Case Of The Transition Theory}

\section{The Nature Of Transition: Types And Pattern}

Transition Theory guides nurses to understand the transition to parenthood, health-illness and situational transitions, which is a developmental type of transition. When Ms. SK's transition is examined within the conceptual framework of Transition Theory, the loss of her father in the last few years, situational transition; diagnosis of arteriovenous malfarm promotion received by her daughter, diagnosis of gestational diabetes and growth retardation in her baby, health-disease transition; It is seen that she is experiencing a transition to motherhood, that is, a developmental transition. Ms. SK's health and illness transitions and transition to motherhood are still ongoing processes. According to the nature of the transition theory, Ms. SK's transitions are sequential, related and multiple transitions.

\section{Physical, Psychological, Social, SpiritualNursing Care According To Transition Theory}

A total of seven interviews were conducted with Ms. SK at 28th and 34th weeks of gestation, second month postpartum, third month, sixth month, 8th and 12th months, and nursing care was provided. Ms. SK was trained on breastfeeding, expressing and storing breast milk, preparation for birth, supporting baby development, newborn screening, vaccination, protection of baby health, common problems in babies, and ensuring baby safety. Power point presentation, breast model, baby model and development support materials were used in the trainings. At the end of the training, within the scope of a doctoral dissertation program aimed at improving infant health, a training booklet developed by taking the opinions of six experts was given. Parents' accessibility to nurses and informative text messages sent to parents ensure continuity of care and increase the quality of care in the pediatric patient group.

\section{Process Indicators of a Healthy Transition}

According to Meleis, development indicators are measurable indicators that show how the transition is progressing. Development indicators; It includes interaction, sense of attachment, positioning, self-confidence and developing coping. Interaction; Ms. SK did not want her baby in the first two trimesters of pregnancy and refused to have any interaction. He looked for different ways to miscarry. However, she wanted to interact with her baby after the birth, and could not achieve this because her baby was sleeping all the time. With the development support practices, she started to interact with her baby by seeing the changes in her baby and made more effort for the health of her baby. The Sense of Attachment; Meleis talked about trust in healthcare professionals, one of the concepts of attachment. Ms. SK contacted us when needed and got answers to her questions. Attachment to healthcare professionals is an indicator of positive transition. The positive results of the practices he learned for the care and development of his baby increased his attachment to healthcare professionals. Development of SelfConfidence and Coping; Another dimension that positively reflects the nature of the transition process is the increase in selfconfidence level with the participation of the individual in the process. With her growing self-confidence, Ms. SK was able to cope with the difficulties of caring for her baby.

\section{Development Indicators of a Healthy Transition}

The first of the two outcome indicators required for a healthy transition is mastery of new skills, the second is the development of a flexible integrative identity. These development indicators increase the quality of lifeFirst of all, Ms. SK accepted her baby. He learned and applied how he can ensure the care, safety and development of his baby. He coped with the problems he encountered, followed the practices we recommended for the development of his baby, paid attention to sleep safety, took the necessary measures to prevent falls and accidents. These situations are indicators of mastery. However, at the end of the second month, Ms. SK's milk was reduced and was not able to give breast milk to her baby for a longer 
period of time. Because he believed that his milk would be cut off because he did not suck the baby. Flexible Identity Development; The nurse should evaluate the health of the individual comprehensively and make the right decision regarding the interventions. Women should understand well how they integrate their multiple roles despite social, cultural, political, economic pressures and constraints. The training we gave to Ms. SK to support baby development and ensure its safety facilitated the transition to parenthood.

As a result; Transition Theory seems to be an appropriate tool to enable nurses to understand different transition experiences. It also has the potential to help nurses to identify appropriate strategies and practices in order to provide adequate assistance and support to parents. 